\title{
IMPORTANCE AND IMPACT OF THE POULTRY RED MITE (DERMANYSSUS GALLINAE) IN LAYER FARMS - ANALYSIS OF FARMERS' PERCEPTION
}

\author{
Miroslav Kjosevski ${ }^{1}$, Danijela Horvatek Tomić ${ }^{2}$, Aleksandar Dodovski ${ }^{3}$ \\ ${ }^{1}$ Department of Animal Hygiene and Environmental Protection, \\ Faculty of Veterinary Medicine - Skopje, \\ Ss. Cyril and Methodius University in Skopje, N. Macedonia \\ ${ }^{2}$ Department of Poultry Diseases with Clinic, Faculty of Veterinary Medicine, \\ University of Zagreb, Croatia \\ ${ }^{3}$ Department of Avian Diseases, Faculty of Veterinary Medicine - Skopje, \\ Ss. Cyril and Methodius University in Skopje, N. Macedonia
}

Received 2 June 2021; Received in revised form 22 August 2021; Accepted 3 September 2021

\begin{abstract}
Poultry red mite (PRM), Dermanyssus gallinae, causes egg drop production, anemia and can be a vector in transmitting diseases. The PRM control mainly focuses on usage of the conventional chemical biocides. The objective of this study was to analyze the farmers' perception regarding the impact, management and control of PRM in Macedonian layer farms. The data were collected with direct on-site visits using a unified questionnaire. In total, 29 poultry farms (28\% of farms in the country), all with conventional cages, were part of this study. The data were analyzed by descriptive statistics, inferential statistics and Naïve Bayes Classifier technique. In 30\% of the poultry farms the farmers had observed that the flock was infested with PRM. In total, 32 different treatments against PRM were reported from the farmers, and three of them were non-biocide treatments. The most used biocides (17\% of the farms) were crude oil, Formalin, Neopitroid ${ }^{\circledR}$ and disinfectants. The highest agreement regarding biocides application among the farms (38\%) was before the production starts. Most of the farmers applied biocides routinely, before the infestation is evident (75\%). The median costs for PRM treatment were $175 €$ per flock, higher in the infested farms $493 \pm 677 €$ compared to non - infested $100 \pm 71 €, p<0.05$. None of the Macedonian farmers included in the study was using monitoring method for PRM infestation, contributing to poor data records. This study highlights the need of developing unified strategy for PRM control included in the Integrated Pest Management in poultry layer farms.
\end{abstract}

Key words: poultry red mite, Dermanyssus gallinae, laying hens, biocides, Naïve Bayes Classifier

\section{INTRODUCTION}

Dermanyssus gallinae or commonly known as poultry red mite (PRM) is the most important ectoparasite affecting laying hens throughout the globe, although the majority of the reports describing its presence and threat to the poultry

Corresponding author: Assist. Prof. Miroslav Kjosevski, $\mathrm{PhD}$

E-mail address: miro@fvm.ukim.edu.mk

Present address: Department of Animal Hygiene and Environmental

Protection, Faculty of Veterinary Medicine - Skopje,

Ss. Cyril and Methodius University in Skopje, N. Macedonia Phone: +38970230587

Copyright: (C) 2021 Kjosevski M. This is an open-access article published under the terms of the Creative Commons Attribution License which permits unrestricted use, distribution, and reproduction in any medium, provided the original author and source are credited.

Competing Interests: The authors have declared that no competing interests exist.

Available Online First: 22 September 2021

Published on: 15 October 2021

https://doi.org/10.2478/macvetrev-2021-0026 industry are from the Northern hemisphere. The research literature studying various aspects of this pest has rapidly increased in recent years (1). In-vitro studies have shown that the PRM completes its life cycle in a little over two weeks. The most favorable environmental conditions for the PRM cycle are the temperature ranges between $10-37^{\circ} \mathrm{C}$ (2) or $20-45{ }^{\circ} \mathrm{C}$ with a relative humidity of $70 \%$ (3), and these ranges coincide with the housing temperatures and the body temperature of poultry. Layer hens infested with the PRM show drop in the egg production and alteration of the egg shell quality $(4,5)$ and in more severe cases anemia can occur which can eventually lead to death due to blood loss $(4,6)$. These are not the only harmful effects that the mite can produce in poultry since it can also serve as a vector in transmitting many 
bacterial and viral diseases including those with zoonotic character (7). PRM is considered as an organism invading mainly poultry but reports of human cases with PRM induced dermatitis are being more frequently published (8). To alleviate this growing concern recommendations for medical practitioners on how to handle human case were recently published (9).

The last published prevalence level in Europe reports data from 1995 to 2013 from 11 countries thus encompassing the period before and after the ban of conventional cages. Out of 309 million poultry, $83 \%$ of the farms were found to be infested with the PRM (8). The only attempt to estimate the prevalence of PRM in Macedonian layer farms was in 2016 using combined methodology (on-site farm visits, post-mortem and phone interviews). This study found that $69 \%$ of investigated farms were infested with the PRM (10). Subsequently, pilot study on four layer farms using morphological and molecular identification of collected mites confirmed the presence of the PRM but also of the predatory mite flora (11). Poultry farming systems in Macedonia are predominantly conventional cages with limited number of farms switching to enriched cages. Currently, there is a proposal that the conventional cages in the existing farms will be allowed until the country's accession to the European Union (EU) while all new constructed farms must have enriched cages as a minimum welfare standard (12).

So far, the control of the PRM was mainly focused on using synthetic acaricides. Since the first report of PRM resistance to pyrethroids in 1997 (13) the research has steadily shifted to alternative control approaches such as biopesticides, plantderived products, vaccines, biological control, physical control and integrated pest management which are all reviewed by Sparagano et al. (1). Persistent use of conventional chemical acaricides leads towards mite resistance (14). However, treatment using orally applied fluralaner can quickly result in improvement of the production traits of the layers (15). The quest for an efficient treatment led to the "fipronil crisis" in several EU countries which caused a withdrawal of millions of table eggs from the market. The reasons for the crisis were high concentrations of fipronil found in the table eggs despite that this product is banned for use in poultry production (16). The data about the methods for treatment and control of PRM in the Macedonian poultry industry were not compiled so far. The objective of this study was to analyze the farmers' perception regarding the significance and the impact of PRM on the poultry production and to identify the present PRM management, control and treatment practices in Macedonian layer farms.

\section{MATERIAL AND METHODS}

\section{Data collection}

The data collection of this study was performed from September to November 2016 by an unified questionnaire and direct on-site farm visits by the data collectors and interviews with the farmers. The used questionnaire has been standardized on European level within the Working Group 1 of the COST Action FA1404 "Improving current understanding and research for sustainable control of the poultry red mite dermanyssus gallinae - COREMI", entitled as "Poultry Red Mite - COREMI European Questionnaire". The questionnaire is comprised of multiple choice, dichotomous and open questions, divided into five main sections: 1 . Production system background production, operation and housing system, equipment, ventilation and manure management, as well as, the age and size of the flock that was in the focus of the survey, i.e. the oldest flock in the farm; 2. PRM Indicators - present and previous infestations of PRM on the farm, opinion about the effect of PRM infestation on egg production, locations of evident PRM presence within the building and about PRM as a reason for itchiness in workers on the farm; 3. Hygiene and PRM treatments - list of all the treatments and hygiene practices used on the oldest flock at the farm, time of application and the achieved effect of each treatment/ practice; 4. Implementation of PRM control - what initiates the PRM control intervention on the farm and usage of certain type of on-farm monitoring system for red mites infestation; and 5. Costs of PRM control - the total financial costs including labor hours for red mites control in the flock of interest, the level of egg production and its possible reduction due to PRM infestation (on-line version of the questionnaire_at https://bit.ly/3BYplly). The information given by farmers during the interviews were recorded by the surveyors, afterword, an electronic transcript was made from the collected data for further analysis.

\section{Poultry farms}

The farms included in this survey were officially registered commercial layer farms in Macedonia, more specifically, farms included in the national eradication disease programs (17). The locations 


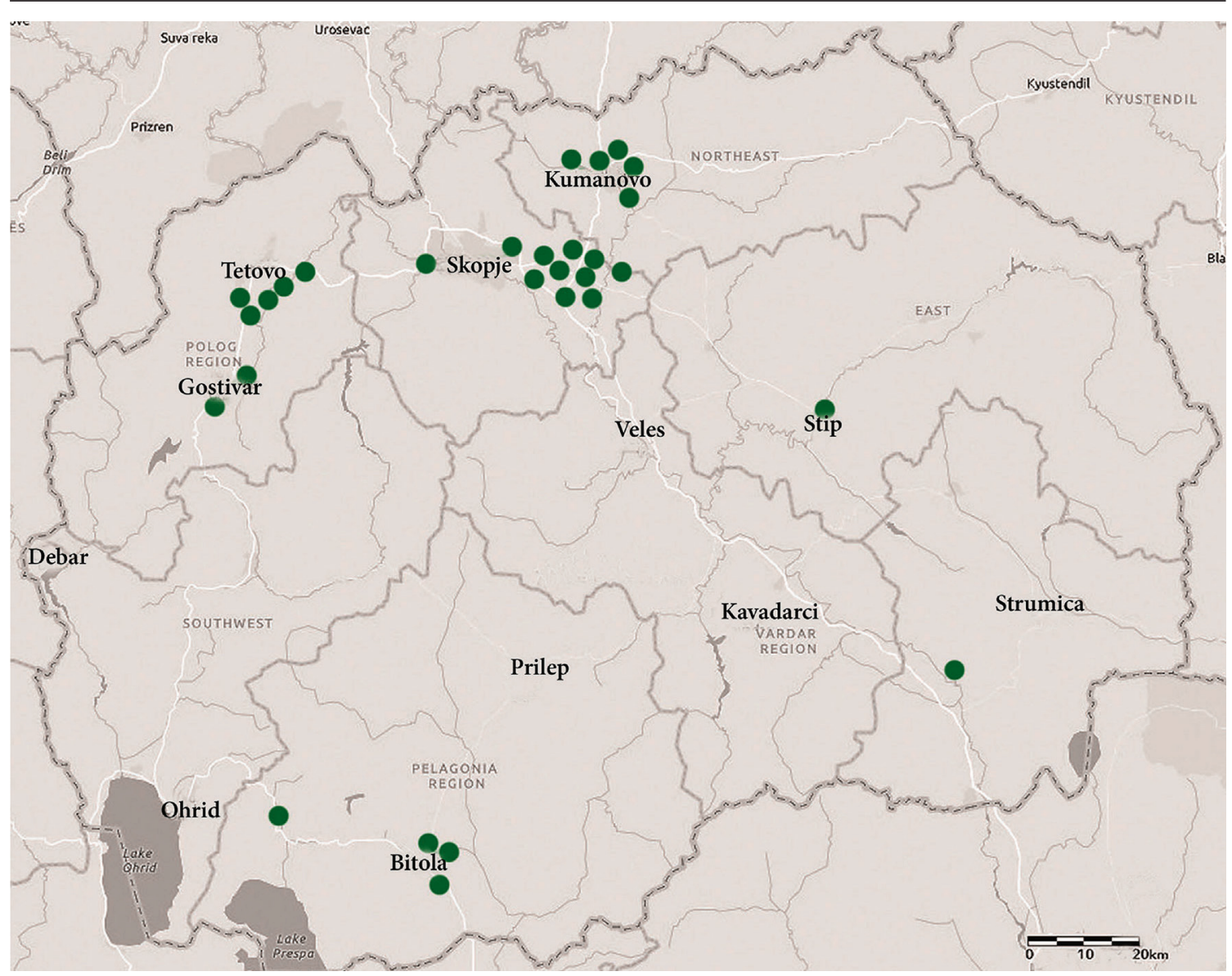

Figure 1. Geographical distribution of commercial layer farms included in the survey (green dots)

of the surveyed farms are presented in Fig. 1. The number of farms investigated by this survey was 29 which represented $28 \%$ of all active registered poultry farms for laying hens in Macedonia (17) ensuring representative sample size for the purpose of this study.

\section{Data analysis and statistics}

The data collected from the survey were summarized and each question was analyzed on group level (national level, including all farms from the survey) using descriptive statistics. Furthermore, cross-tabulation between different questions was performed in order to make deeper analysis of the responses given by the farmers. These data were later analyzed using inferential statistics for making conclusions on the population level i.e., poultry farms at national level. Thus, the following additional analytical tests were performed:

i) cross-tabulation frequency distribution and

Pearson Chi-Square test for determining any relations between the type of manure management and farmer's believes for current or past presence of PRM in the flock (PRM infestation). Additionally, the reason for starting the PRM treatment was cross-tabulated with PRM infestation in the flock, along with opinion about the reduction of egg production due to PRM and the costs for PRM control;

ii) Mann Whitney $U$ test was used for detecting differences between PRM farm infestation groups and the age, the size of the flock, the costs and the labor hours spent for PRM control. Performing this test, the groups formed according the different opinions about the reduction of egg production due to PRM were also compared according the age of the flock; and

iii) Spearman's rank-order correlation was performed to determine any relation between PRM control costs and the age, the size of the flock and the labor hours spent for PRM control. The latter was additionally tested for correlation with the size of the flock and identified egg drop in the flock, while the egg drop was tested against the age and size of the flock. For these analyses the significance threshold was set at $\mathrm{p}=0.05$. 
The last level of analysis was cross-tabulation of three variables (questions) where the relation of PRM infestation and production with two additional factors was analyzed. The PRM infestation was observed in relation to the size of the farm together with PRM control costs. Likewise, the PRM infestation was checked for any relations with the age of the flock and the present egg drop. Additional links between the size of the farm, the labor hours spent for PRM control and the present egg drop were also analyzed in this section. The conducted analyses in this cross-tabulation of three variables were based on descriptive statistic and on the Naïve Bayes Classifier technique. The Naïve Bayes was used for analyzing the relations between three variables (responses on three different questions) by detecting how much the posterior probability of one factor (perception of farmers) is proportional to the a-priory values of two other variables - in this case perception of farmers for two other topics (two questions from the survey). Thus, the posterior probability $p$ of a dependent variable $C$ for the given predictors $X$ was calculated by:

$$
p\left(C_{j} \mid X\right) \propto p\left(C_{j}\right) \prod_{k=1}^{d} p\left(x_{k} \mid C_{j}\right)
$$

where $k$ represents the level of independent variable and $j$ is the dependent variable, while in the modeling the normal function for $p\left(x_{k} \mid C_{j}\right)$ was used, with $\mu$ as a mean and $\sigma$ as standard deviation:

$$
p\left(x_{k} \mid C_{j}\right)=\frac{1}{\sigma_{k j} \sqrt{2 \pi}} \exp \left(\frac{-(x-\mu)^{2}}{2 \sigma_{k j}}\right)
$$

All the data processing in this study was performed using Microsoft Excel (2010), Microsoft Corporation for data entry and preprocessing, and STATISTICA (data analysis software system), v8.0, StatSoft, Inc. (2008) for the data analytics.

\section{RESULTS}

The production system of all farms that took part in the survey was conventional cages. Two types of manure handling systems were present on the farms: manure pit system (66\% of the farms) and manure belt system ( $31 \%$ of the farms), while one farm (3\%) had "other" type of manure handling system. The age of the flocks ranged from 18 to 96 weeks with median age of 65.5 weeks. The size of the flocks ranged from 600 to 29000 with mean size of $7460 \pm 8010$ birds per flock. Considering the PRM infestation of Macedonian poultry farms, around $30 \%$ (9 farms) declared that the observed flock is/was infested. More detailed results regarding the perception of the farmers about the PRM infestation and its severity are presented in Fig. 2.

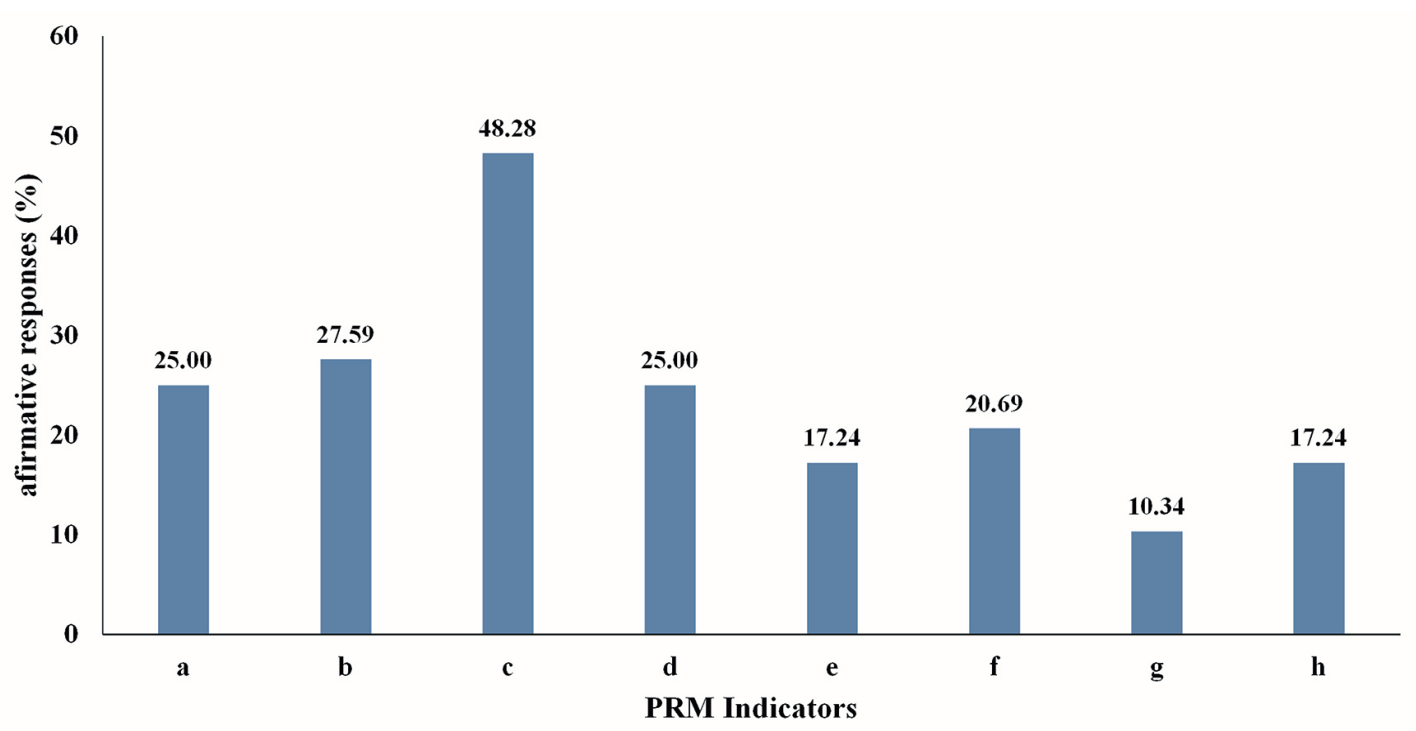

Figure 2. The opinions of the farmers regarding the PRM indicators, i.e. percentage of the farmers that had confirmatory responses regarding: a) The farmer thinks that the flock is having PRM infestation at the moment when the survey was conducted; b) The farmer had seen PRM in this flock in the past; c) The farmer thinks that the mite is causing a reduction in egg production in the flock; d) The farmer sees red mites on the housing; e) The farmer sees red mites in cracks and crevices; f) The farmer sees clustered spots of red mites on the furniture; g) The farmer sees bloodspots or mites on eggs; h) The farmer or the animal care staff complains about red mites and itching skin 
In total, 32 different treatments against PRM were reported from the farmers. Three treatments from the reported were non-biocide: mechanical cleaning and water washing used in three farms and manure removal reported by one farm. The rest, 29 treatments were application of various biocides. The frequency of biocide usage among farms is presented in Fig. 3. The most frequently used biocides were reported on maximum of five different farms, while the other identified biocides in most cases were encountered in just one farm. The most used biocides (17\% of the farms) were crude oil, Formalin, Neopitroid ${ }^{\circledR}$ and biocides that are part of the disinfection procedure, while $10 \%$ of farmers were using Corvin $\mathrm{WP}^{\circledR}$, K-Othrine ${ }^{\circledR}$, Ekocid $^{\circledR}$, Neostomosan $^{\circledR}$ and Sebacil ${ }^{\circledR}$ (Fig. 3).

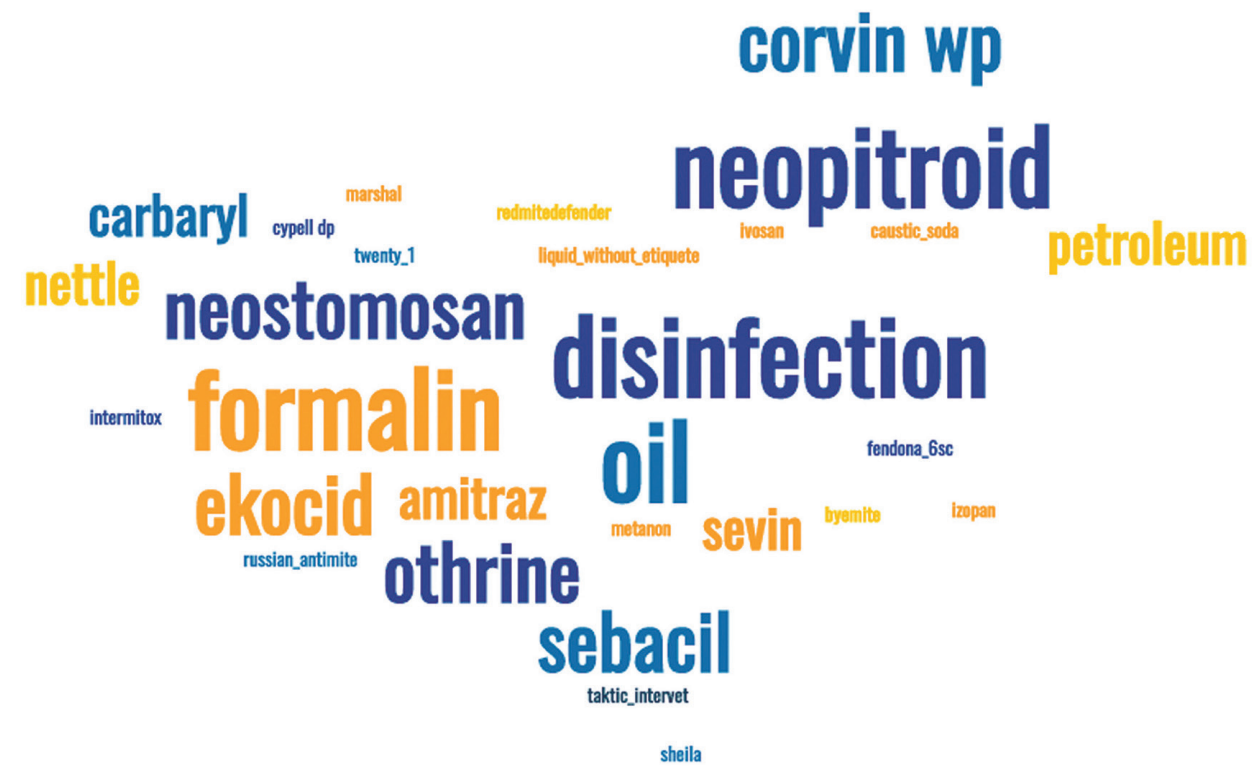

Figure 3. Word cloud of the biocides used in poultry farms in Macedonia against PRM, the bigger the word the higher the number of farms using that biocide. The frequency of biocide usage among farms is ranging from 1 farm (the smallest text, e.g. sheila) to 5 farms (the biggest text, e.g. Neopitroid ${ }^{\circledR}$ ) for one biocide

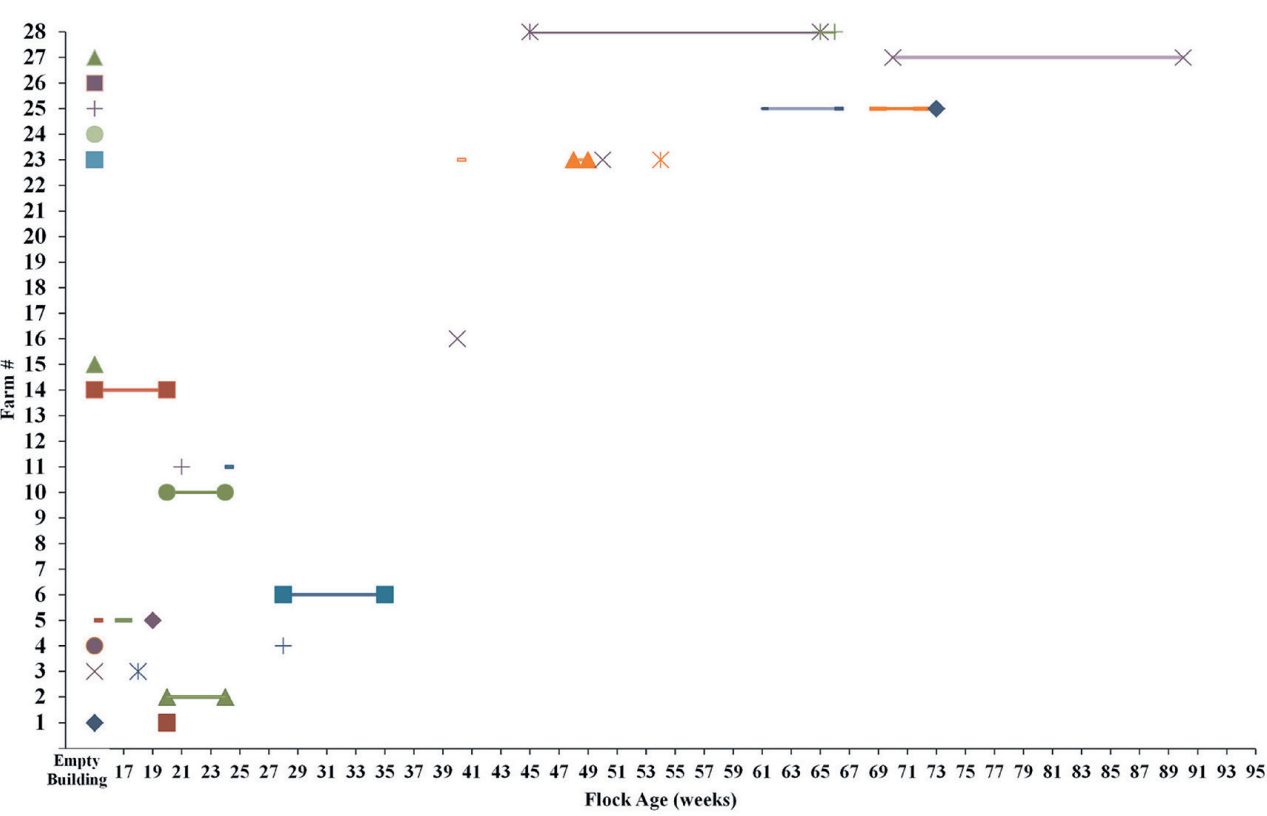

Figure 4. Time of biocides applications against PRM in regards to flock age in weeks (horizontal axis) in different farms (vertical axis). Each marker represents different applications of the biocide treatment (not necessarily different biocide) and the connected markers represent the reapplied treatment with the same biocide at the marked weeks of the flock age 
The time of application of the biocides in 38\% of the farms was before the start of the production process, however, the program of biocides application after the introduction of the flock was different and unique for most of the farms (Fig. 4). The number of different treatments per flock ranged from 0 to 6 , where the highest number of farms, i.e. $31 \%$ reported three treatments and $28 \%$ of the farms reported a single treatment. Considering the effect of anti PRM treatments i.e., the reduction of PRM infestation in the flock, from the total 58 treatments, the farmers confirmed the effect of reducing the PRM infestation in $59 \%$ of cases, while $36 \%$ of responses were that the farmers didn't know whether the treatment achieved the expected results.

The treatments against PRM as part of the implementation of PRM control were mostly applied "Routinely (regardless of red mite presence)" 39\% of responses and "Before mites are seen" and/or
"When mites are first seen (low numbers)", 36\% of farmers. Additionally, none of the farmers were using red mite monitoring method such as mite traps for determining the presence of red mites in their flocks.

Different types of PRM control costs (money spent on treatment, labor hours spent and drop in egg productions) are presented in Table 1.

The number of farms that use manure pit systems in regards to absence or presence of PRM infestation was 12 and 7, while those with the manure belt systems were 8 and 1, respectively. However, there was no statistically significant difference between the manure systems considering the PRM infestation, $\chi^{2}(2, N=29)=4.19, p=0.12$. Similarly, no statistical difference was found between the reason for starting the PRM treatment with the PRM infestation, egg production due to PRM and the costs for PRM control (Table 2).

Table 1. Costs of red mite control presented as median and 25\% and 75\% quartiles, Q1 and Q3 respectively

\begin{tabular}{lccc}
\hline Type of costs & $\begin{array}{c}\text { Number of } \\
\text { responses (n) }\end{array}$ & Median & Range \\
\cline { 2 - 4 } $\begin{array}{l}\text { Red mite control products for the flock of } \\
\text { interest (EUR per flock) }\end{array}$ & $\begin{array}{c}12 \\
\text { flock size } \\
\left(1.2-27 * 10^{3} \text { birds) }\right.\end{array}$ & 175 & 125 \\
\hline $\begin{array}{l}\text { Labor hours spent on red mite control } \\
\text { in the last month for the flock of interest } \\
\text { (hours) }\end{array}$ & 12 & 10 & 250 \\
\hline $\begin{array}{l}\text { Drop in the current egg production caused } \\
\text { by the red mites in the flock of interest (\%) }\end{array}$ & 11 & 20 & 13 \\
\hline
\end{tabular}

Table 2. Cross-tabulation of implementation of PRM control with the PRM infestation, farmer's opinion about the reduction of egg production due to PRM and the costs of PRM control

\begin{tabular}{lccccc}
\hline & & \multicolumn{2}{c}{ Implementation of PRM control - starting the treatment } \\
\cline { 3 - 6 } & Routinely & $\begin{array}{c}\text { Before mites } \\
\text { are seen }\end{array}$ & $\begin{array}{c}\text { Mites are } \\
\text { first seen (low } \\
\text { numbers) }\end{array}$ & $\begin{array}{c}\text { Mites are clearly } \\
\text { visible (medium } \\
\text { numbers) }\end{array}$ \\
\hline \multirow{2}{*}{ PRM infestation } & Yes (no. farms) & 3 & 4 & 5 & 1 \\
\hline No (no. farms) & 8 & 6 & 5 & 0 \\
\hline $\begin{array}{l}\text { Opinion for egg } \\
\text { drop }\end{array}$ & Yes (no. farms) & 3 & 6 & 7 & 1 \\
\hline Costs for PRM control, EUR (median) & 350 & 4 & 3 & 0 \\
\hline
\end{tabular}


The opinion of the farmers regarding the effect of PRM on egg drop in relation to the age of the flock was not significant i.e., the age of the flock was $55.57 \pm 22.00$ weeks in those farmers that believe the PRM reduce the egg production, and the age was $67.57 \pm 19.60$ weeks, $p=0.15$ in the group of farmers with opposite opinion. The relation between the PRM infestation with the age, size of the flock, costs and labor for PRM control is presented in Fig. 5. The PRM control costs were higher in the infested farms in comparison to the ones without present or past infestation, $493 \pm 677$ and $100 \pm 71$ euros respectively, $p=0.02$ (Fig. 5). The values of all other variables in Fig. 5 were higher in the PRM infested flocks but they were not statistically significant. No significant correlations were found between "Costs of PRM control" with the other farm/flock parameters, as well as, between the parameters within this main section (Table 3).

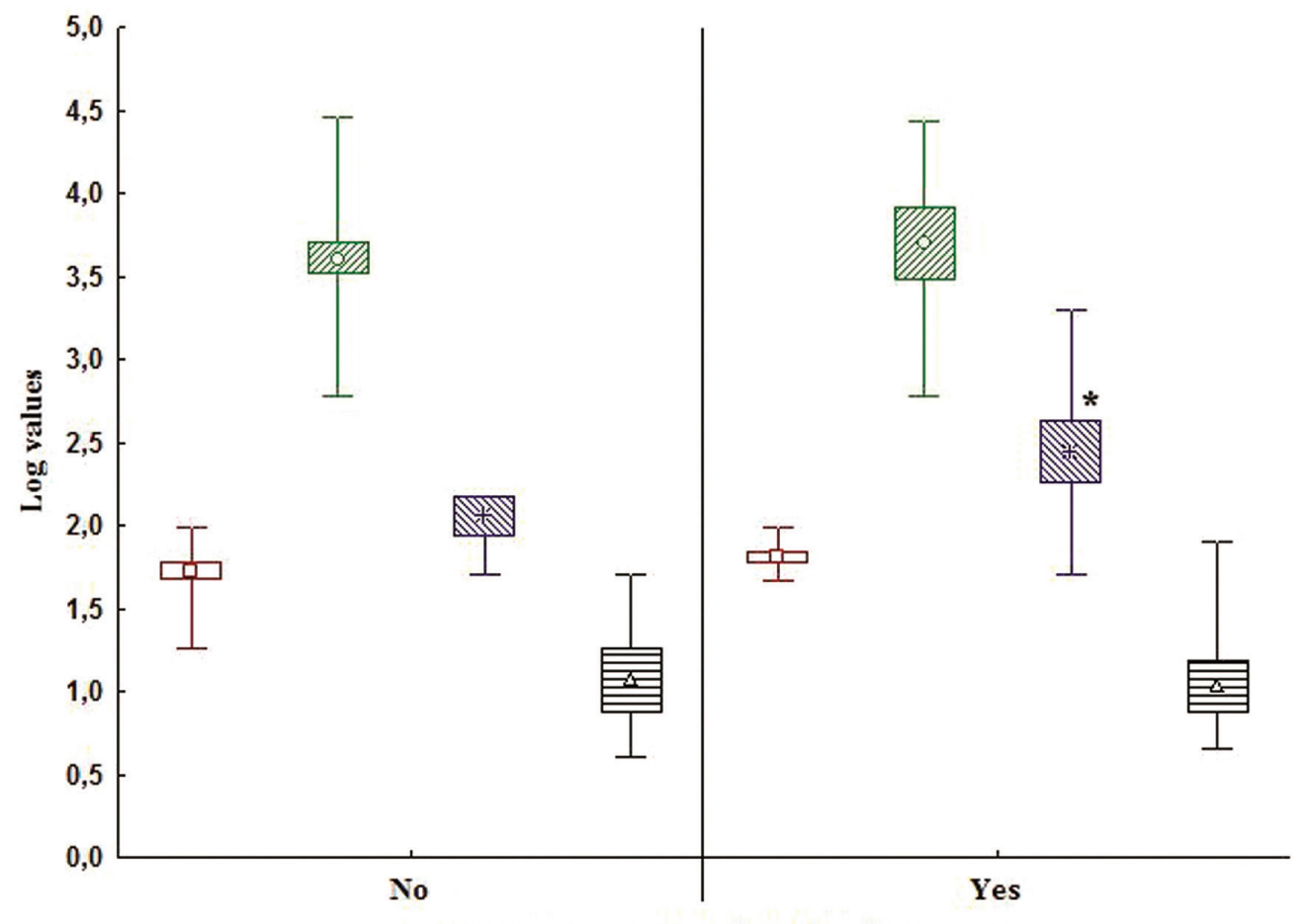

PRM infestation in the flock (current or past)

Figure 5. Comparison of flock age $\square$, flock size costs for PRM treatments and labor hours spent against PRM E with the PRM infestation (yes) or no infestation (no) flocks (subsets divided by chart midline). The markers represent the means, boxes SD and whiskers range values. The values of the variables are represented as log values. $(* \mathrm{p}<0.05)$

Table 3. Correlation coefficients between the parameters regarding "Costs of PRM control" and other parameters from the survey

\begin{tabular}{lcccc}
\hline Parameter 1 & Parameter 2 & n & Correlation (R) & Significance (p) \\
\hline \multirow{3}{*}{ Costs for PRM treatment } & Age of the flock & 12 & 0.38 & 0.22 \\
& Size of the flock & 12 & 0.28 & 0.38 \\
& Labor for PRM control & 10 & 0.05 & 0.90 \\
\hline \multirow{2}{*}{ Egg drop production } & Age of the flock & 19 & -0.03 & 0.90 \\
& Size of the flock & 19 & -0.29 & 0.23 \\
\hline Labor for PRM control & Labor for PRM control & 9 & 0.24 & 0.53 \\
\hline
\end{tabular}


Considering the flock size, costs for PRM treatment and PRM infestation, the farms that had/have PRM infestation $(n=7)$ have between 1200-27000 birds/flock and the spent costs for PRM treatment are ranging from 50 to $2000 €$, while the farms that are free from PRM $(n=5)$ have 4000-8200 birds/flock and for PRM treatment spent from 0 to $150 €$. The Naïve Bayes truly correctly classified all farms with No PRM infestation (100\% correct classification), while correct classification of the farms with PRM infestation based on the flock size and costs for PRM treatment was 71\%. Those farms that were not correctly classified as PRM infested farms had small size of the flock (3500 and 4500 birds) and relatively low costs (250 and 50€).

The farms with PRM infestation $(n=7)$ are with flock from 53-75 weeks old and egg drop production from 0 to $25 \%$, while in the farms without PRM infestation $(n=12)$, are with flock of 18 to 96 weeks old and egg drop production between 0 to $50 \%$. The percentage of truly classified farms with No PRM infestation was 90\% and with PRM infestation was $67 \%$. The incorrect predicted case classified by model as No PRM infestation was a farm with a flock of 53 weeks old and egg drop reduction of $25 \%$, while the incorrectly classified farms as PRM infested farms where those with 54, 68, 72 weeks old hens and egg drop production of $10 \%, 0 \%$ and $0 \%$.

In total, nine farms responded on the three questions about flock size, labor hours and egg drop production. The egg drop production reached $20 \%$, while $44 \%$ of these farms stated no drop in egg production. The flock size ranged from 600 to 27000 birds and labor hours from 0 to 80 . The highest labor hours was without egg drop and the second highest (50 labor hours) was in the farm with $20 \%$ egg drop production, while the range of the flock size in accordance with the labor hours was with higher variance from 80 hours in a flock of 3500 , through 10 hours in 18000 till 0 labor hours in a flock of 8200 birds, all without egg drop reduction. The Naïve Bayes Classifier model considering the presence and absence of egg drop production has $50 \%$ and $43 \%$ incorrect cases, respectively.

\section{DISCUSSION}

The study analyzes the perception of the farmers about the significance and the impact of PRM on the poultry production and identifies the present PRM management, control and treatment practices in Macedonian layer farms. This study was part of the European scientific network initiative within the frame of the European Cooperation in Science and Technology (COST) Action "Improving current understanding and research for sustainable control of the poultry red mite Dermanyssus gallinae COREMI". The COREMI network has developed an unified questionnaire with the following aims and benefits: i) identification of present integrated pest management practices and current red mite controls in poultry farms; ii) the prevalence of the PRM data on country level; iii) the impact of infestation on the productivity of commercial farms and estimation of the financial costs associated with red mite infestation and control; and iv) establishing closer collaborative links between the industry and scientists to support future research into improving red mite control and maintaining research relevance to the industry (on-line description of COREMI Network: https://www.coremi.eu/working-groups/ wg-1-developing-alternative-control-measures. html). The unified questionnaire was also used in this study for collecting data and findings for Macedonian layer farms in order to be comparable and to contribute to the current and future findings about PRM in other European countries and beyond.

The production and housing systems for laying hens in the country are mostly based on conventional cages (18), although some of the farms have introduced enriched cages for their flocks. The surveys of this study were performed in farms with conventional cages, predominantly with manure pit system, while the geographical distribution and the number of the studied farms were ensuring the representativeness of the poultry farms in the country. Therefore, the results of this study might be considered as a reflection of the actual farmer's perception regarding PRM in the poultry sector of the country. Moreover, the size of the farms also reflects the capacity of Macedonian layers from small farms managed by family holdings to larger commercial farms. Furthermore, the wide variations of the size and age of the flocks in the farms was an opportunity to study the associations between these factors and PRMs.

Regarding the PRM infestation, Waap, Nunes (19) reports a discrepancy of the infestation rate obtained by questionnaire $(62.5 \%)$ and by placing of traps for mite collection $(95.8 \%)$. The reason for the discrepancy was attributed to the low awareness of the farmers about the current infestation on their farm possibly due to low mite numbers. This coincides when comparing our previous study in which we found infestation rate of $69 \%$ using combined methodology, such as: direct on-farm visits, post-mortem examination and interview with 
farmers (10) with this study in which we obtained infestation rate of $30 \%$ using the questionnaire. The farmers' perception is less sensitive to the method of choice for estimating the prevalence rate on the farm level compared to the other evidence-based methods (traps, farm inspection, hen inspection, etc.).

As stated previously all surveyed farms had conventional cage systems with manure removed by the belt or dropped in the pit. In both instances the hen has very limited and short contact with the droppings and no contact with the manure. In our study we did not find any correlation between PRM infestation and the type of manure management system. Some authors were comparing the infestation levels at the farms with the different housing systems and had found that free range systems have higher mite densities than farms with caged systems $(20,21)$. Free range farms differ significantly from farms with cages regarding management and husbandry practices including manure handling so the difference in PRM infestation levels can be expected. In farms with caged systems management and husbandry practices are more consistent and equipment driven as in our case.

Recent studies found that the level of infestation measured through mite densities were not correlated with the age and the size of the flock $(19,22)$. However, in Italy it was found that smaller farms had higher infestation levels but this did not depend on the size of the flock rather on the husbandry practices (23). Contrary, the results of this study according to the Naïve Bayes classifier technique (comparison of PRM infestation with the size of the flock and costs for PRM treatment) indicated that smaller farms with low costs for PRM treatment are most probably free from PRM. This result is difficult to interpret unequivocally because according to our knowledge no study about the PRM prevalence/infestation had used this approach so far, therefore several explanations can be made. One explanation might be that smaller flocks are more easily managed for prevention of PRM than larger flocks. Likewise other explanation can be that farmers of smaller flocks are not aware of the PRM infestation on their farms and spend less money and attention than the farmers of larger farms.

The PRM can persist on the farm throughout the whole production period of the layers which is equivalent to a period of at least 56 weeks with observed seasonality in the level of infestation which usually peaks in the summer (24). Therefore, this might be the reason for absence of significant difference in flock age between the farms with and without PRMs. Thus, it can be assumed that age of the flock cannot be considered as a decisive factor for infestation. However, farm classification based on the PRM infestation in combination with other two parameters age of the flock and egg drop production have shown different results. The infested farms had narrower age range of the flock (53-75 weeks) compared to the wide age range of non infested farms. This was the main reason for the high percentage of correctly classified cases of farms with no PRM infestation by the Naïve Bayes classifier technique. Consequently, it may be concluded that a PRM infestation is somehow related to certain flock age range and is a dynamic state difficult to frame it. Thus, different analytical approaches should be taken in consideration for determining the importance of the flock age in relation to the PRM infestation of the farm.

The egg drop production was higher in the non infested farms, according the Naïve Bayes. Although there are many reports in the literature about the relation of the egg drop production with the PRM infestation, this has not been proven by valid scientific methods. The widely cited paper on this issue from Cosoroaba (4) is a case report and lacks a diagnostic exclusion of other pathogens that can cause egg drop in layer hens. Thus, the overall classification of this model indicates that the egg drop production due to PRM infestation most probably is not properly perceived and recorded by the farmers. This indicates that the classification technique regarding the egg drop production is inconclusive. In this context, the opinion of the farmers regarding the PRM impact on the egg drop production is divided, i.e. almost half of the responders think that PRM is causing reduction in egg production of their flock. The surveyed farmers reported $10-30 \%$ reduction of egg production, however these reports were mostly based on the farmers' general perception instead of factual monitoring and analysis. Additionally, there was no association between the established opinion by the farmer on this matter with the age of the flock and the size of the farm which further confirms that the egg production losses are only based on the farmer's perception. One of the major issues related to this is that in commercial farming is really hard, almost impossible, to identify which performance parameters are affected by PRM presence (15).

The farmers in this study reported that PRM were mostly seen in the housing i.e. the whole building, followed by the cracks and crevices. This is in line with the well-known tendency of PRMs in the farms to be located in the cracks and crevices of the equipment $(1,23)$. Almost one fifth of 
respondents reported complain about PRM presence and itching skin in Macedonian farms. This is fully in line with the present literature where at least dermatitis is reported among the workers in poultry farms $(9,25,26)$. However, this issue is becoming more serious as other concerns for human health have been identified (9). This leads to the need for better protection of farmers and poultry workers, as a risk group that is highly exposed to PRM.

The PRM treatments on farm level that not include biocides were reported in only four farms and these treatments were referring to mechanical cleaning, water washing and manure removal. Probably most of the other farms have these practices as well, but the survey indicates that farmers do not perceive these hygiene practices as a treatment against PRM. One of the most important biosecurity measures in poultry production is regular mechanical cleaning and/or water washing of empty or occupied facilities. Maintaining of good hygiene practices is beneficial in removal of large number of mites and all developmental stages $(24,27)$. Other conventional methods mostly used for PRM treatment include application of inert compounds (as diatomaceous earth or silica, powder or liquid). Combination of such products and mechanical cleaning drastically reduce mite population (more than $90 \%$ ) as stated by Alves et al. (27). Therefore, these types of nonbiocide treatments and improved hygiene practices should be promoted among farmers as important tools for fight against PRM.

The most used biocides in PRM treatment in Macedonian farms were crude oil, Formalin, Neopitroid ${ }^{\circledR}$ and biocides that are part of disinfection procedures. These biocides were followed by Corvin $^{\circledR}$ WP, K-Othrine ${ }^{\circledR}$, Ekocid ${ }^{\circledR}$, Neostomosan ${ }^{\circledR}$ and Sebacil ${ }^{\circledR}$ as frequently used biocides. These, along with most of the other reported biocides are not on the national or European list of approved biocides against PRM. Currently on the European market there is only small number of allowed and registered biocides, to be safely used in poultry houses, either full or empty, against PRM (according to European Chemicals Agency). Unfortunately, the mites' resistance has been recorded in the last decade, mainly on pyrethroids, organophosphates, carbamates, and formamidines (28). This is probably the main reason why the majority of manufacturers/farmers also use illicit biocides, treatments and substances.

One of the biggest crises to hit egg producers is certainly the Fipronil-related case that occurred in 2017 (16). This event shows the negative side-effect of application of substances that can harm both human and animal health, but on another hand, also encouraged the EU to launch new activities and measures. Some of those involve higher controls and broader range of analyzed residues for detection of the fraudulent use of biocides and similar substances, as reported in the "Overview report of a series of fact-finding missions on biocides in EU member states 2017-2018" (29). Additionally, the process for availability on the market and use of biocidal products is long and strongly regulated at EU level. As previously mentioned, report by DG Sante (29) is explaining, the EU Directive 98/8/EC is regulating placement of biocidal products on the market (short name Biocidal Products Directive (BPD)), and is in force from September 2013. Under the BPR (and previously BPD), the active substances must first be approved at EU level, typically for a period of 10 years, before the biocidal products containing them are authorized by the Member States (MS). Companies seeking authorization for their biocide products can choose to follow one of several different authorization processes depending on the type of product concerned and the number of countries in which they wish to sell it. These processes could be via the reference MS, several MSs or via Union Authorization. Anyhow, this process should satisfy high safety standards in order to be allowed for commercial and practical use. To date, most of the biocidal products available on the market of the MSs visited continue to be covered by national systems or practices established prior to the BPR. The European Chemicals Agency operates an EU Register for Biocidal Products (R4BP), a dedicated information technology (IT) platform which is used for submitting applications and for exchanging data and information (29). This process is ensuring higher protection of human, animal and environmental health, but on the other side, the long process of authorization and limited number of approved biocides encourage the usage of illicit biocides and substances by poultry farmers.

Reviewing the list of biocides used in Macedonian poultry farms against PRM highlight several major points. There is great diversity of biocides used without a uniformed biocidal approach between the farmers. Additionally, some of the farmers used chemical agents without any information about the type of the biocide or the active component, which raises food safety concerns. The list of biocides used indicates that poultry farmers are willing and seeking any kind of solution for PRM control in their farms. However, for more than one third of all treatments the farmers are not familiar with the effects of the biocides. Similar diversity was found 
at the time when the biocides are applied at the farm. No unified approach, shared best practice or widely accepted protocol is present on country level. The highest agreement between farms was applying the biocides before introducing the flock in the empty buildings which is widely recommended, especially for avoiding chemical residues in eggs and as anti - resistance strategy $(30,31)$. The reason for using biocides is mainly as prevention and before any identification of PRM by monitoring tools. This is also confirmed with the statements emphasized by the farmers about "routinely" and "before" or "when mites are seen" application of treatments against PRM. Additional confirmation to this was the absence of any significant link between starting the PRM treatment with other parameters in the farm (PRM infestation, egg production or PRM control costs). No monitoring strategy and methods for PRM were integrated in the poultry farms management, therefore, the awareness about the infestation and impact is recorded only where the PRM presence is highly evident.

The median costs of $175 €$ per flock for PRM management in the surveyed flocks was a bit lower than other research reports across Europe. Thus the study in Portugal estimates average costs of $30.24 € / 1000$ hens in the flock (19), the costs in cage systems in France were 4.33€/100 hens or converted in floor space $0.85 € / \mathrm{m}^{2}(32)$, or the study by Van Emous (33) presented $0.15 €$ per hen/year for treatment costs. For better comparison, after conversion, at Macedonian poultry farms the costs were $25.15 €$ for 1000 hens or $0.03 €$ per hen. These lower costs for PRM treatment might be due to various reasons, such as: less frequent PRM treatments/flock, available biocides with lower prices on the market, no suitable cost records at the farm etc. Additionally, small number of responses to this question also indicated poor records of the poultry farms on this matter. The PRM treatment costs were not associated with the age or size of the flock, neither with the labor which might indicate that the usage of biocides is random without suitable analysis, monitoring of the PRM situation and/or poor records for the costs or labor hours. In the context of monthly labor hours spent on PRM control the median was 10 or converted on 1000 hens the median was 1.45 (interquartile range of 0.87-1.88). These labor hours were slightly higher than the study in Portugal where the number was 0.40 (0.14-1.78) for 1000 hens (19). However, these figures are questionable since there were no reliable records on this issue in any farm included in the study. This absence of proper labor recordings might also be the reason for the absence of any kind of correlation between this variable and costs for PRM treatment, decreased egg production or size of the flock. Likewise, low classification predictability of the model in regards to the flock size, labor hours for PRM control and egg production due to PRM together with the high variability of these parameters among the farms supports the previous conclusions of absent of proper records of labor hours and egg drop production. Therefore, the Naïve Bayes classifier technique was not able to have high percentage of correct classifications and drawing any association between these three parameters.

The results of this study are urging for an immediate strategic action against PRM infestation in Macedonian poultry farms. Therefore, in order to reduce the PRM damage and proper control of these pests without affecting the food safety of utmost importance is to implement the following measures country wide: i) usage of non-chemical preventive measures in the farms; ii) developing standard operating procedures for PRM control and treatments; iii) usage of EU approved biocides for PRM treatment; iv) introducing standard monitoring tools for PRM presence; v) reliable on-farm records for egg production, labor hours and costs for PRM control and treatment; and vi) unified approach by all poultry farmers in the country in the combat against PRM in poultry farms. These recommendations should be part of one Integrated Pest Management as a strategy for control of pest species while taking care of sustainability of animals, humans and the environment (34). Although the suggested recommendations are only based on the findings of this study they are fully in compliance with the proposed eight steps for IPM Strategies for controlling PRM by Decru, et al. (35) consisted of: 1. Prevention and population suppression; 2. Monitoring population; 3. Treatment decision based on monitoring and thresholds; 4. Non-chemical treatments; 5. Use of selective/specific synthetic pesticides; 6. Reduction of pesticide use; 7. Anti-resistance strategies; and 8. Evaluation. These proposed approaches should be considered as national policy for proper control of PRM as one of the biggest threats to poultry health, production and welfare.

\section{CONCLUSION}

According the poultry farmer's perception, the PRM infestation was estimated to be present at $30 \%$ of the poultry farms, which is much lower in comparison with other methods for prevalence estimation. Thus, the farmers' perception is a less 
sensitive method for estimating the prevalence rate at farm level. Considering any predictors for PRM infestation, the smaller farms with low costs for PRM treatment are most probably free from PRM. The relation of PRM infestation with the flock age range is very dynamic and different analytical approaches should be considered for proper analysis. Considering the PRM treatment, in general, farmers do not perceive non-biocides and hygiene practices as a treatment against PRM and the most used biocides were crude oil, Formalin, Neopitroid ${ }^{\circledR}$ and biocides that are part of the disinfection procedures. Likewise, most of the reported biocides are not on the national or European list of approved biocides against PRM. There was a great diversity of biocides used and the time of application without any uniform biocidal approach between farmers which also raises food safety concerns. It was evident that there is an absence of unified approach, shared best practice or widely accepted protocol on country level. There was a low or complete absence of proper data recordings in the poultry farms regarding several important factors: monitoring of PRM, egg production and losses due to PRM, costs for PRM treatment/ management or labor hours. This study indicates the importance of an immediate strategic action in the frame of Integrated Pest Management Strategy for controlling PRM infestation in Macedonian poultry farms. The proposed approaches should be integrated in the national policy for pest control and management of PRM in poultry farms.

\section{CONFLICT OF INTEREST}

The authors declare that they have no potential conflict of interest with respect to the authorship and/or publication of this article.

\section{ACKNOWLEDGMENTS}

This study is a direct output from our work within the EU COST Action FA1404: Improving current understanding and research for sustainable control of the poultry red mite Dermanyssus gallinae (COREMI). Part of the activities was covered by the University project: Monitoring, morphological and molecular identification and phylogenetic characterization of thepoultry red mite (Dermanyssus gallinae) in the poultry farms in Republic of Macedonia (No. 02-314/25-10). Additionally, we are deeply grateful to our students Matea Mateva, Neda Kuzmanovska, Nadja Georgieva, Goran Mladenovski and Stefan Tekovski for their contribution in this study.

\section{AUTHORS' CONTRIBUTIONS}

MK and AD developed the design of the study, work concept, survey adaptation and interviews with the farmers. MK was involved in data analysis and together with AD interpreted the results. DHT analyzed the usage of biocides and European legal framework for this topic. All three authors were involved in the literature review, discussion and critical revision of the manuscript.

\section{REFERENCES}

1. Sparagano, O.A.E., George, D.R., Harrington, D.W.J., Giangaspero, A. (2014). Significance and control of the poultry red mite, Dermanyssus gallinae. Annu Rev Entomol. 59(1): 447-466.

https://doi.org/10.1146/annurev-ento-011613-162101 PMid:24397522

2. Maurer, V., Baumgärtner, J. (1992). Temperature influence on life table statistics of the chicken mite Dermanyssus gallinae (Acari: Dermanyssidae). Exp Appl Acarol. 15(1): 27-40.

https://doi.org/10.1007/BF01193965

PMid:1511637

3. Nordenfors, H., Höglund, J., Uggla, A. (1999). Effects of temperature and humidity on oviposition, molting, and longevity of Dermanyssus gallinae (Acari: Dermanyssidae). J Med Entomol. 36(1): 68-72.

https://doi.org/10.1093/jmedent/36.1.68 PMid:10071495

4. Cosoroaba, I. (2001). Massive Dermanyssus gallinae (De Geer 1778) invasion in battery-husbandry raised fowls in Romania. Revue Méd Vét. 152(1): 89-96.

5. Chauve, C. (1998). The poultry red mite Dermanyssus gallinae (De Geer, 1778): current situation and future prospects for control. Vet Parasitol. 79(3): 239-245.

https://doi.org/10.1016/S0304-4017(98)00167-8

6. Kilpinen, O., Roepstorff, A., Permin, A., Nørgaard-Nielsen, G., Lawson, L.G., Simonsen, H.B. (2005). Influence of Dermanyssus gallinae and Ascaridia galli infections on behaviour and health of laying hens (Gallus gallus domesticus). Br Poult Sci. 46(1): 26-34.

https://doi.org/10.1080/00071660400023839

PMid:15835249

7. Huong, C.T., Murano, T., Uno, Y., Usui, T., Yamaguchi, T. (2014). Molecular detection of avian pathogens in poultry red mite (Dermanyssus gallinae) collected in chicken farms. J Vet Med Sci. 76(12): 1583-1587.

https://doi.org/10.1292/jvms.14-0253

PMid:25649939 PMCid:PMC4300372 
8. George, D.R., Finn, R.D., Graham, K.M., Mul, M.F., Maurer, V., Moro, C.V., et al. (2015). Should the poultry red mite Dermanyssus gallinae be of wider concern for veterinary and medical science? Parasites Vectors 8, 178.

https://doi.org/10.1186/s13071-015-0768-7

PMid:25884317 PMCid:PMC4377040

9. Cafiero, M.A., Barlaam, A., Camarda, A., Radeski, M., Mul, M., Sparagano, O., et al. (2019). Dermanysuss gallinae attacks humans. Mind the gap! Avian Pathol. 48(sup1): S22-S34.

https://doi.org/10.1080/03079457.2019.1633010

PMid:31264450

10. Dodovski, A., Stefanovska, J., Radeski, M. (2016). Preliminary findings of poultry red mite in Macedonian poultry farms. 2nd COST Conference and Management Committee1-3 June 2016; Zagreb, Croatia; Book of abstracts: 17.

11. Dodovski, A., Popova, Z., Radeski, M. (2018). Update on the poultry red mite research activities in Macedonia. 4th COST Conference-Improving current understanding and research for sustainable control of the poultry red mite dermanyssus gallinae -COREMI; 1-2 November 2018; Cluj-Napoca, Romania: Scientia Parasitologica Vol. 19: 20.

12. Ministry of agriculture, forestry and water economy (2019). Law on Amendments and Modifications to the Law on protection and welfare of animals. In: Ministry of agriculture, forestry and water economy. https:/ener.gov.mk/default. aspx?item $=$ pub_regulation\&subitem $=$ view_reg_ detail\&itemid $=50272 \% 20$.

13. Beugnet, F., Chauve, C., Gauthey, M., Beert, L. (1997). Resistance of the red poultry mite to pyrethroids in France. Vet Rec. 140(22): 577-579. https://doi.org/10.1136/vr.140.22.577 PMid:9194299

14. Pugliese, N., Circella, E., Cocciolo, G., Giangaspero, A., Horvatek Tomic, D., Kika, T.S., et al. (2019). Efficacy of $\lambda$-cyhalothrin, amitraz, and phoxim against the poultry red mite Dermanyssus gallinae De Geer, 1778 (Mesostigmata: Dermanyssidae): an eight-year survey. Avian Pathol. 48(sup1): S35-S43. https://doi.org/10.1080/03079457.2019.1645295 PMid:31362523

15. Sleeckx, N., Van Gorp, S., Koopman, R., Kempen, I., Van Hoye, K., De Baere, K., et al. (2019). Production losses in laying hens during infestation with the poultry red mite Dermanyssus gallinae. Avian Pathol. 48(sup1): S17-S21.

https://doi.org/10.1080/03079457.2019.1641179

PMid:31298932
16. DG SANTE (2017). Information note on EU measures concerning the illegal use of fipronil on some poultry farms (10 August 2017). Newsletter of DG Health and Food Safety 11.08.2017.

https://ec.europa.eu/newsroom/sante/newsletter-archives/4774

17. Food and Veterinary Agency (2017). National control programme for reducing the prevalence of Salmonellosis in laying hens, paretn flocks, broilers, incubatory stations (Gallus gallus) in Republic of Macedonia for the period of 2017 - 2020. Skopje, 2017. http://fva.gov.mk/mk/nacionalen-kontrolen-plan-namaluvanje-prisustvo-salmoneloza

18. Nikolova, N., Kocevski, D. (2017). Problems and perspectives of poultry production in the Republic of Macedonia. Maced J Anim Sci. 7(1-2): 89-95.

19. Waap, H., Nunes, T., Mul, M.F., Gomes, J., Bartley, K. (2019). Survey on the prevalence of Dermanyssus gallinae in commercial laying farms in Portugal. Avian Pathol. 48(sup1): S2-S9.

https://doi.org/10.1080/03079457.2019.1606415 PMid:30982335

20. Guy, J.H., Khajavi, M., Hlalel, M.M., Sparagano, O. (2004). Red mite (Dermanyssus gallinae) prevalence in laying units in Northern England. Br Poult Sci. 45 (Suppl 1): S15-S16. https://doi.org/10.1080/00071660410001698001 PMid:15222342

21. Fiddes, M.D., Le Gresley, S., Parsons, D.G., Epe, C., Coles, G.C., Stafford, K.A. (2005). Prevalence of the poultry red mite (Dermanyssus gallinae) in England. Vet Rec. 157(8): 233-235.

https://doi.org/10.1136/vr.157.8.233 PMid:16113169

22. Gunnarsson, E. (2017). Poultry red mites in Swedish laying hen flocks [master's thesis]. [Uppsala, Sweden]: Swedish University of Agricultural Sciences, 48 p.

23. Sparagano, O., Pavlićević, A., Murano, T., Camarda, A., Sahibi, H., Kilpinen, O., et al. (2009). Prevalence and key figures for the poultry red mite Dermanyssus gallinae infections in poultry farm systems. Exp Appl Acarol. 48(1-2): 3-10. https://doi.org/10.1007/s10493-008-9233-Z PMid:19160060

24. Nordenfors, H., Höglund, J. (2000). Long term dynamics of dermanyssus gallinae in relation to mite control measures in aviary systems for layers. Br Poult Sci. 41(5): 533-540. https://doi.org/10.1080/713654991 PMid:11201430 
25. Sigognault Flochlay, A., Thomas, E., Sparagano, O. (2017). Poultry red mite (Dermanyssus gallinae) infestation: a broad impact parasitological disease that still remains a significant challenge for the egglaying industry in Europe. Parasites Vectors 10, 357. https://doi.org/10.1186/s13071-017-2292-4 PMid:28760144 PMCid:PMC5537931

26. Valiente Moro, C., De Luna, C.J., Tod, A., Guy, J.H., Sparagano, O.A.E., Zenner, L. (2009). The poultry red mite (Dermanyssus gallinae): a potential vector of pathogenic agents. Exp Appl Acarol. 48(1-2): 93-104. https://doi.org/10.1007/s10493-009-9248-0 PMid:19205905

27. Alves, L.F.A., de Oliveira, D.G.P., Pares, R.B., Sparagano, O.A.E., Godinho, R.P. (2020). Association of mechanical cleaning and a liquid preparation of diatomaceous earth in the management of poultry red mite, Dermanyssus gallinae (Mesostigmata: Dermanyssidae). Exp Appl Acarol. 81(2): 215-222.

https://doi.org/10.1007/s10493-020-00497-z PMid:32378067

28. Abbas, R.Z., Colwell, D.D., Iqbal, Z., Khan, A. (2014). Acaricidal drug resistance in poultry red mite (Dermanyssus gallinae) and approaches to its management. World's Poult Sci J. 70(1): 113-124. https://doi.org/10.1017/S0043933914000105

29. DG SANTE (2019). Overview report of a series of fact-finding missions on biocides in EU member states 2017-2018. Luxembourg: Publications Office of the European Union, 2019.

https:/op.europa.eu/s/sinW
30. Ducatelle, R., Van Immerseel, F. (2011). Management and sanitation procedures to control Salmonella in laying hen flocks. In: F. Van Immerseel, Y. Nys, M. Bain (Eds.), Improving the safety and quality of eggs and egg products (pp. 146-162). Woodhead Publishing Limited https://doi.org/10.1533/9780857093929.2.146

31. Di Palma, A., Giangaspero, A. (2021). Laelapid and Dermanyssid mites of medical and veterinary interest. Reference Module in Biomedical Sciences https://doi.org/10.1016/B978-0-12-818731-9.00048-3

32. Lubac, S., Dernburg, A., Bon, G., Chauve, C., Zenner, L. (2003). Problematique et pratiques d'elevage en poules pondeuses Dans le sud est de la France contre les nuisibles : poux rouges et mouches. Cinquièmes Journées de la Recherche Avicole; 26 et 27 mars 2003; Tours 2003.

33. Van Emous, R. (2005). Wage war against the red mite! Poultry Int. 44, 26-33.

34. Barzman, M., Bàrberi, P., Birch, A.N.E., Boonekamp, P., Dachbrodt-Saaydeh, S., Graf, B., et al. (2015). Eight principles of integrated pest management. Agron Sustain Dev. 35(4): 1199-1215. https://doi.org/10.1007/s13593-015-0327-9

35. Decru, E., Mul, M., Nisbet, A.J., Vargas Navarro, A.H., Chiron, G., Walton, J., et al. (2020). Possibilities for IPM strategies in European laying hen farms for improved control of the poultry red mite (Dermanyssus gallinae): details and state of affairs. Front Vet Sci. 7, 565866. https://doi.org/10.3389/fvets.2020.565866 PMid:33282928 PMCid:PMC7705068 